\title{
Dikkat Eksikliği ve Hiperaktivite Bozukluğu Olan Çocuklarda Grup Aktivitesinin Benlik Algısı Üzerine Etkisi
}

The Effect of Group Activity on Self-Perception in Children with Attention Deficit and Hyperactivity Disorder

Cemre BAFRALI ${ }^{1}$, Onur ALTUNTAŞ ${ }^{2}$

${ }^{1}$ Erg., Hacettepe Üniversitesi, Sağlık Bilimleri Fakültesi, Ergoterapi Bölümü, Ankara

${ }^{2}$ Dr. Öğr. Üyesi., Hacettepe Üniversitesi, Sağlık Bilimleri Fakültesi, Ergoterapi Bölümü, Ankara

\section{ÖZ}

\begin{abstract}
Amaç: Dikkat eksikliği ve hiperaktivite bozukluğu tanılı çocuklarda grup aktivitesinin benlik algısı üzerine etkisini incelemek idi. Gereç ve Yöntem: Çalışmamıza ilköğretim 3. ve 4. sınıfta okuyan Dikkat Eksikliği ve Hỉperaktivite Bozukluğu tanısı olan ve ilaç kullanan 6 birey dâhil edildi. Benlik algısı Piers-Harris Öz Kavram Ölçeği ile değerlendirildi. Grup aktivitelerinin çocukların ilgi alanlarına göre oluşturulması için çocuklar ve aileleri ile bireysel görüşme yapıldı. 6 hafta boyunca 6 çocuk ile haftada 1 saat grup aktivitesi yapıldı. Piers- Harris Öz Kavram Ölçeği müdahale sonrasında tekrar uygulandı. Sonuçlar istatiksel olarak karşılaştıııldı. Sonuçlar: Çalışmamıza katılan 6 birey de erkekti. Yaş ortalamaları 9,33 $\pm 0,51$ idi. Illk ve son değerlendirmelerde Piers-Harris Öz Kavram Ölçeğinin mutluluk, kaygı, popülarite, davranış ve uyma, fiziksel görünüm, zihinsel ve okul durumu alanlarında istatistiksel olarak anlamlı bir farklııık bulunmamıştır $(p>0,05)$. Tartışma: Bu çalışmamızda ilk ve son değerlendirme sonuçlarında benlik algısında önemli gelişmeler olmasına rağmen bu fark sonuçlara yansımamıştır. Dikkat Eksikliği ve Hiperaktivite Bozukluğu olan çocuklara uygulanan grup aktivitelerinin ailelere verilen benlik algısı eğitimleri ile desteklendiği uzun dönem takipler ile incelenen çalışmalara intiyaç olduğunu düşünmekteyiz.
\end{abstract}

Anahtar Kelimeler: Dikkat Eksikliği ve Hiperaktivite Bozukluğu; Grup aktivitesi; Benlik algısı

\section{ABSTRACT}

Purpose: To investigate the effect of group activities on self-perception of children with Attention Deficit and Hyperactivity Disorder. Material and Methods: Six individual diagnosed with Attention Deficit and Hyperactivity Disorder, who were studying in 3rd and 4th grade, and taking medication, were included. The self-perception was assessed using the Piers-Harris Self-Concept Scale. Individual interviews were held with children to develop group activities according to their interests. Group activity was conducted with 6 children for 6 weeks, 1 hour per week. The Piers-Harris Self-Concept Scale was reapplied and the effect of the intervention was examined after the intervention. The results were analysed statistically. Results: All children participated in the study were boys. The average age was $9,33 \pm 0,51$. There was no statistically significant difference in the areas of happiness, anxiety, popularity, behavior and conformity, physical appearance, mental and school status of the Piers-Harris Self-Concept Scale between the pre and post assessments $(p>0,05)$. Conclusion: Although there were clinical improvements in self-perception, this difference was not reflected on the results. We think that group activities applied to children with Attention Deficit and Hyperactivity Disorder need long term follow-up studies supported by family self-awareness trainings.

Key Words: Attention Deficit and Hyperactivity Disorder; Group activity; Self-perception 
Benlik algısı, kişinin kendini algılamasına ve değerlendirmesine yönelik geliştirdiği bir yapıdır ve kişinin kendini nasıl gördüğünü ve değerlendirdiğini açıklamaktadır. Ebeveynler ve arkadaşlar çocuğun benlik algısını etkileyen önemli kişilerdir. Bu bağlamda sosyal etkileşim çocukta benlik algısının oluşmasında destek olan önemli bir süreç olduğu belirtilmektedir (Yavuzer, 2000).

Dikkat Eksikliği ve Hiperaktivite Bozukluğu (DEHB) olan çocuklarda olumsuz benlik kavramı oldukça sık görülmektedir (Dumas ve Pelletier, 1999; Cohen ve Thompson, 1982; Horn, Wagner ve Lalongo, 1989; Barber, Grubbs ve Cottrell, 2005; Kanay ve Girli, 2008; Mazzone vd. 2013; Gentschel ve McLaughlin, 2000). DEHB olan çocuklar olumsuz davranışlar göstermeleri ve sosyal ilişkilerinde güçlük yaşamaları nedeni ile sıklıkla evde, okulda ve yaşadıkları diğer çevrede eleştirilere ve cezalandırmalara maruz kalmaktadırlar. Özellikle ilköğretim yıllarında gerek akademik gerekse iletişimsel anlamda yaşanan sorunlar ve başarısızlıklar nedeni ile çocuklar kendilerini olumsuz ifadelerde betimlemekte ve kendilerine olan güvensizliklerini ve mutsuzluklarını belirtmektedirler (Kanay,2006).

Araştırmalar, DEHB olan çocukların sosyal becerilerdeki yetersizlikler nedeniyle, sosyal ortamda akranlarıyla etkileşimde bulunma ve yakın dostluklar geliştirme konusunda zorluk yaşadığını göstermektedir (Barber, Grubbs ve Cottrell, 2005). Yaşanan bu zorluklar ile birlikte sosyal reddin kümülatif etkisinin de düşük benlik saygısı ve olumsuz benlik algılamasına neden olabileceği belirtilmektedir (Gentschel ve McLaughlin, 2000).

DEHB olan çocuklar davranışlarından dolayı genellikle olumsuz yönde dikkat çekmektedir (Barber, Grubbs ve Cottrell, 2005). DEHB olan çocukların davranışsal alandaki eksikliklerin sonucu ortaya çıkan sosyal içe dönüklükte uygun sosyal becerilerin olmaması, yaşının gerektirdiği davranışların gerisinde olma ya da sosyal olarak uyumsuz olma davranışı ve düşük benlik saygısı görülmektedir (Kanay,2006).

Bazı çalışmalarda zayıf veya düşük benlik saygısının DEHB olan çocuklarda olumsuz sonuçlarla ilişkili olduğunu belirtildiği için benlik algısı veya benlik saygısı tedavilerin odağında yer almaktadır (Kanay,2006). Çalışmalarda, DEHB'li çocuklarda benlik kavramı gelişimiyle ilişkili olan 'duyguları ifade etme, istek, başarı, güçlü yanlar, yetenekler, yeni benlik imajı yaratma, odaklanma, olumlu düşünme, karar verme (Durualp ve Aral, 2010) alanlarının' dikkate alındığı destek grupları ile olumlu benlik algısını geliştirmeye odaklanılması gerektiği vurgulanmaktadır (Barber, Grubbs ve Cottrell, 2005; Kanay, 2006).

Ergoterapistler, benlik algısını artırma rolünü üstlenmelerine karşın yapılan çalışmalarda, müdahalenin benlik kavramındaki değişime yönelik etkinliğinde az kanıt sağladığını ve bu alanda yapılan çalışmalara intiyaç olduğunu belirtmiştir. (Willoughby, King ve Polatajko, 1996; Benson, J., \& Clark, F. 1982; Missiuna, C., \& Pollock, N. 2000 ). Bu bilgiler ışığında çalışmamızın amacı; dikkat eksikliği ve hiperaktivite bozukluğu olan çocuklarda grup aktivitelerinin benlik algısı üzerine etkisini araştırmaktır.

\section{GEREÇ VE YÖNTEM}

Çalışmamız Helsinki Deklarasyonuna uygun olarak yürütüldü, araştırmaya katılan tüm olgular değerlendirme öncesinde bilgilendirildi ve ailelere aydınlatılmış onam formu imzalatıldı. Çalışmamıza 5'i 3. sınıfta ve 1'i 4. sınıfta okuyan 6 erkek çocuk dâhil edildi. Çalışmaya dâhil edilen DEHB altı çocuk, olumlu benlik algısının gelişimine yönelik grup aktivitelerinin yer aldığı çalışmaya 2 Mart -13 Nisan 2017 tarihleri arasında ilköğretim okulunun aynalı salonunda 6 hafta boyunca haftada 1 gün 1 saat süre ile katıldı. Değerlendirme ölçekleri olarak Demografik Bilgi Toplama Anketi, benlik algısı için Piers-Harris Çocuklarda Öz Kavram Ölçeği (PHÇÖÖ) kullanıldı. 6.haftanın sonunda PHÇÖÖ tekrar uygulandı. Sonuçlar istatiksel olarak karşılaştırıldı.

\section{Veri Toplama}

1)Demografik Bilgi Toplama Anketi

Tüm çocukların ailelerinden değerlendirmeye başlamadan önce aşağıdaki demografik bilgiler alındı; çocuğun adı, çocuğun cinsiyeti, çocuğa konulan tanı ve çocuğun öğrenim durumu ve kimlerle yaşadığı kaydedildi.

2) Çocukların ilgi ve isteklerini belirlemek için çocuklarla görüşme yapıldı. Çocuklara; hangi aktiviteleri sevdikleri, hangi aktivitelerde kendilerini başarılı hissettikleri, hangi aktiviteleri yapmak istedikleri ve ilgi duydukları aktivitelerin neler olduğu sorularak çocukların ilgi ve istekleri belirlenip grup aktivitelerinin oluşturulmasında referans oluşturuldu.

3) Piers-Harris Çocuklarda Öz Kavram Ölçeği

Piers-Harris (1964) tarafından geliştirilen, Öner (1996) ve Çataklı (1985) tarafından Türkçe' ye uyarlaması yapılan "Çocuklarda Öz-Kavramı Ölçeği” çocukların kendilerine yönelik tutumlarını, duygu ve düşüncelerini değerlendirmeyi amaçlamaktadır. Ölçek, "Davranış", "Zihinsel/Okul durumu”, "Fiziksel görünüm”, "Kaygı”, "Sosyal beğenirlik ya da Gözde 
olma" ve "Mutluluk" alt ölçeklerinden oluşmaktadır. 80 tanımlayıcı ifadeden oluşan ölçek, "evet" ya da "hayır" şeklinde yanıtlanır. Yanıtlar, bir anahtar ile puanlanır. Elde edilen puanlar kuramsal olarak 0 ila 80 arasında değişir. Yüksek puan olumlu benlik kavramının varlığına, düşük puan ise olumsuz benlik kavramının varlığına işaret eder. (Sarı ve Cenkseven, 2008).

\section{Müdahale}

Çalışmamızda aktiviteler; aktivite esnasında çoklu seçenekler arasından karar verme becerilerinin kullanımını destekleme, kendilerine ve arkadaşlarına karşı sorumluluk alma becerilerini geliştirme, çocukların kendilerine ait bir eser oluşturmaları ve bu eseri anlatmalarına fırsat tanıma, kendi istek ve özelliklerine yönelik farkındalık oluşturma, kendilerini nasıl algıladıklarına yönelik olumlu ve olumsuz özelliklerini ifade etmeleri amacı ile oluşturuldu. Bu amaçlar doğrultusunda seçilen aktivitelerin anlamlı olması için çocuklarla uygulanan görüşmeden elde edilen bilgiler ışığında grup aktiviteleri çocukların ilgi, beceri ve isteklerine yönelik oluşturuldu.

1. Hafta: Grup üyelerinin birbiriyle tanışmasını sağlama

2. Hafta: Bireyin kendisini temsil eden ifadelerini, kendileri hakkında sevdikleri özelliklerini, duygu ve düşüncelerini sembol, müzik, dans veya sözlü ve sözsüz iletişim kullanarak kendini ifade etme

3. Hafta: Aktivite esnasında karar verme yetisiyle aktivite devamlılığını sağlama, çoklu seçenekler arasından karar verme becerisini geliştirme

4. Hafta: Bir probleme karşı çözüm üretme ve aktiviteler sırasında kendisine ve arkadaşlarına karşı sorumluluk alma

5. Hafta: Kendi olumlu ve olumsuz özelliklerini ifade etme, hangi özelliğe sahip olunursa olunsun kendilerini sevmelerine yönelik farkındalık oluşturma 6. Hafta: Hayal dünyalarına ve kendi istek ve özelliklerine yönelik farkındalık oluşturma, sözlü ve sözsüz iletişim yollarıyla duygularını diğer katılımcılara ifade etme amaçlanarak aktiviteler oluşturulmuştur.

6 hafta boyunca uygulanan grup aktivitesinin ardından çocuklara başarı belgesi verildi.

İstatistiksel analiz: İstatiksel analizler için SPSS 20 for Windows" programı kullanıldı. Sonuçlar aritmetik ortalama ve standart sapma $(X \pm S S)$ olarak ifade edildi. Grubun verileri Wilcoxon Signed Ranks Testi ile karşılaştırıldı ve istatiksel anlamlılık düzeyi $p<0.05$ olarak kabul edildi.

\section{SONUÇLAR}

Çalışmamıza DEHB tanılı 6 çocuk dâhil edildi. Grup aktivitesine katılan çocukların demografik özellikleri Tablo 1'de verilmiştir. Çalışmaya katılan çocukların yaş ortalamaları 9,33 $\pm 0,51$ idi. Çalışmaya katılan çocukların tamamı erkektir. Demografik bilgi toplama anketinden elde edilen bulgulara göre çalışmaya katılan çocukların tamamı kardeşleri, anne ve babasıyla birlikte yaşamakta idi. Grup aktivitesine katılan çocukların PHÇÖÖ sonuçları Tablo 2'de verilmiştir. PHÇÖÖ ortalama puanı 1. Değerlendirmede ilk değerlendirmede 50,50 $\pm 13,95$ iken ikinci değerlendirme de 54,66 $\pm 18,15$ olduğu tespit edilse de bu değişim istatistiksel olarak anlamlı bulunmadı $(p>0,05)$.

Tablo 1. Demografik Özellikler

\begin{tabular}{lcc}
\hline Demografik Özellikler & $\mathbf{n}$ & $\%$ \\
\hline Cinsiyet & 6 & 100 \\
Erkek & & \\
Yaş & 3 & 50,0 \\
9 & 2 & 33,3 \\
10 & 1 & 16,6 \\
11 & $9,33 \pm 0,51$ & \\
Yaş ortalaması & & 83,3 \\
Ögrrenim Durumu & 5 & 16,6 \\
\hline Ilkokul 3. Sınıf & 1 & \\
Illkokul 4. Sınıf & & \\
\hline
\end{tabular}


Tablo 2. Grup aktivitesine katılan çocukların tedavi öncesi ve sonrası Piers- Harris Öz Kavram Ölçeği

(PHÇÖÖ) değerlendirme sonuçları

\begin{tabular}{|c|c|c|c|}
\hline P.H.Ç.Ö.Ö & $\begin{array}{l}\text { 1.Değerlendirme } \\
\text { Ort } \pm \text { SS }\end{array}$ & $\begin{array}{l}\text { 2.Değerlendirme } \\
\text { Ort } \pm \text { SS }\end{array}$ & $\mathbf{p}$ \\
\hline $\begin{array}{l}\text { Mutluluk, Doyum } \\
\text { (Min: 0, Max: } 13 \text { puan) }\end{array}$ & $9,83 \pm 3,18$ & $10,33 \pm 3,66$ & ,461 \\
\hline $\begin{array}{l}\text { Kaygı } \\
\text { (Min: } 0, \text { Max: } 13 \text { puan) }\end{array}$ & $8,50 \pm 2,88$ & $8,50 \pm 2,73$ & ,891 \\
\hline $\begin{array}{l}\text { Popülarite, Sosyal Beğeni ya da Gözde Olma } \\
\text { (Min: 0, Max: } 11 \text { puan) }\end{array}$ & $7,50 \pm 2,42$ & $8,16 \pm 4,07$ & ,577 \\
\hline $\begin{array}{l}\text { Davranış ve Uyma-Konformite } \\
\text { (Min: 0, Max: } 16 \text { puan) }\end{array}$ & $12,33 \pm 3,44$ & $13,00 \pm 4,00$ & ,461 \\
\hline $\begin{array}{l}\text { Fiziksel Görünüm } \\
\text { (Min: 0, Max: } 16 \text { puan) }\end{array}$ & $7,66 \pm 1,75$ & $8,50 \pm 2,25$ & ,197 \\
\hline $\begin{array}{l}\text { Zihinsel ve Okul Durumu } \\
\text { (Min: } 0 \text {, Max: } 10 \text { puan) }\end{array}$ & $4,66 \pm 2,16$ & $6,16 \pm 1,60$ & ,066 \\
\hline $\begin{array}{l}\text { TOPLAM } \\
\text { (Min:0, Max: } 80 \text { puan) }\end{array}$ & $50,50 \pm 13,95$ & $54,66 \pm 18,15$ & ,225 \\
\hline
\end{tabular}

\section{TARTIŞMA}

DEHB olan çocuklarda grup aktivitesinin benlik algısına etkisini incelediğimiz çalışmamızda ilk ve son değerlendirme sonuçlarında önemli gelişmeler olmasına rağmen bu farkın sonuçlara yansımadığı tespit edilmiştir.

Mayberry'e göre terapistler benlik kavramı unsurundaki birçok faktöre yönelik müdahale yaparken, müdahale sonrasında kişilerde büyük değişiklikler olmasına rağmen kişilerin kendileri hakkında hissettiklerini yani benlik algılarını çok az değiştirdiklerini dile getirmiştir. Bizim çalışmamızda da çocuklarda görülen değişime rağmen benlik algısında anlamlı fark bulunamaması Mayberry'i destekler niteliktedir (Mayberry, 1990).

Benlik kavramının ergoterapistlerin birçoğu tarafından her yaştaki çocuklar için açık veya dolaylı bir tedavi amacı olarak kullanıldığı ve engelli çocuklarda benlik algısının araştırımasında kullanılan üniter yaklaşımın engelli çocukların benlik algısında farklılıklar göstermesine rağmen terapistlere etkin ve verimli bir müdahale planı için rehber oluşturmadığı ifade edilmiştir. (Mayberry, 1990).

Olumlu benlik algısı geliştiren çocuk, akranlarıyla olumlu sosyal ilişkiler kurarken, olumsuz benlik algısına sahip çocuklar ise sosyal açıdan akran ilişkilerine zarar verirler.(Uluyurt, 2012) Birçok çalışmada çocukların benlik kavramının akran ilişkilerinin kalitesi ile ilişkili olduğu belirlenmiştir (Sarı ve Cenkseven, 2008). Bu durum çalışmamızda; çalışmanın başında çok sessiz kalan ve yalnız kalmayı tercih eden Olgu 4'ün çalışma sürecinde arkadaşlarının yanına gitmesi, onlarla sohbeti başlatıp sürdürmesi, kendi sınıfına götürüp panoları anlatması ve diğer katılımcıların birbirleriyle olan iletişimlerinin artması ile gözlemlendi.

Grup aktivitelerinin; benlik kavramı gelişiminin ilişkili olduğu; duygularını ifade etme, güçlü yanlarını ve yeteneklerini fark etme, odaklanma, olumlu düşünme, sorumluluk alma alanlarında olumlu bir etkisinin olduğunu; Olgu5'in olumlu özelliklere yönelik yapılan bir aktivitede "Benim sevdiğim bir özelliğim yok ki!" ifadesinin ardından ilerleyen haftalarda yapılan benzer bir aktivitede olumlu özelliklerini rahatça ifade edebilmiş ve bu özelliklerini sarı renkli bir kalem kullanarak "Sarı yazıyı altın harflerle yazdım, çok güzel çizdim." ifadesiyle ve diğer çocukların kendilerine ait özelliklerini çok daha rahat ifade etmeleri ile gözlemlendi. Gözlemlenen bu durumu PHÇÖ' nin Zihinsel ve Okul Durumu faktöründeki puan artışı da desteklemektedir.

Çocukların annelerinden "Çalışmaya gelmek için can atıyor, yaptıklarınızı gelip bize ve arkadaşlarına anlatıyor." ifadeleriyle, Olgu3'ün annesinin “'istanbul'dan dayısı gelecek onu karşılamaya gidecekken ben çalışmaya gitmek istiyorum, kaçıramam diyerek dayısına gitmeyi kabul etmedi." ifadesinin yanında çocukların çalışmaya istekli ve motive olarak gelmeleri, çalışmanın bitmesini istememeleri bize grup aktivitelerine katılım için motivasyonu sağladığımızı göstermektedir. Bu 
durumun da çalışmamızda yer alan grup aktivitelerinin çocukların ilgi ve isteklerine göre oluşturmasından kaynakladığı düşünülmektedir. Harter'in motivasyonun benlik algısı üzerinde etkili olduğu ifadesinden (Willoughby, King ve Polatajko, 1996) yola çıkarak çocuklar için yapılandırılmış grup aktivitelerinin, çocukların motivasyonunu artırarak çocukların benlik algısı gelişimini destekleyeceği düşünülmektedir.

Çocuklardaki görülen önemli farklılıklara rağmen bu farklılıkların sonuca yansımamasını PHÇÖÖ'nin benlik algısı üzerine grup aktivitelerinin etkisini yansıtmakta yeterli bir ölçek olmadığından ve çocukların çalışmamızda elde ettikleri kazanımları günlük yaşamda sürdüremediklerinden kaynaklı olabileceği düşünülmektedir. Çocukların grup aktiviteleri ile elde ettikleri kazanımların günlük yaşama yansıması için ailelere benlik algısı hakkında eğitim verilmesinin faydalı olacağını ve bu aile eğitimi ile grup aktivitelerinin birlikte uygulandığı çalışmaların yapılmasının da sürdürülebilir benlik algısını destekleyeceği düşünülmektedir.

Sonuç olarak ileride yapılacak olan çalışmalarda daha çok seans sayısını içeren ve uzun dönem takiplerle yapılan grup aktivitelerinin benlik algısına etkisinin incelenmesinin yararlı olacağı düşünülmektedir.

\section{Kaynaklar}

Adana, F., Arslantaş, H., \& Şahbaz, M. (2012). Lise öğrencilerinin benlik kavramlarını algılama biçimleri ve ilişkili faktörler. Psikiyatri Hemşireliği Dergisi, 3(1), 22-29.

Barber, S., Grubbs, L., \& Cottrell, B. (2005). Self-perception in children with attention deficit/hyperactivity disorder. J Pediatr Nurs, 20(4), 235-245.

Cohen, N. J., \& Thompson, L. (1982). Perceptions and attitudes of hyperactive children and their mothers regarding treatment with methylphenidate. Can J Psychiatry, 27, 40-42.

Benson, J., \& Clark, F. (1982). A guide for instrument development and validation. Am J Occup Ther, 36(12), 789-800

Çataklı, M. (1985). Transliteral equivalence and eeliabilty of the Turkish version of the PiersHarris Children's SelfConcept Scale (Yayınlanmamış Yüksek Lisans Tezi). Boğaziçi Üniversitesi Sosyal Bilimler Enstitüsü, İstanbul.

Dumas, D., \& Pelletier, L. (1999). A study of self-perception in hyperactive children. MCN Am J Matern Child Nurs, 24(1), 12-19.

Durualp, E., \& Aral, N. (2010). Anasınıfına devam eden altı yaş çocuklarının sosyal uyum ve becerilerine oyun temelli sosyal beceri eğitiminin etkisi. Hacettepe Üniversitesi Eğitim Fakültesi Dergisi (HU Journal of Education), 39, 160-172.

Gentschel, D. A., \& McLaughlin, T. F. (2000). Attention deficit hyperactivity disorder as a social disability: Characteristics and suggested methods of treatment. J Dev Phys Disabil, 12(4), 333-347.

Horn, W. F., Wagner, A. E., \& Lalongo, N. (1989). Sex differences in school-aged children with pervasive attention deficit hyperactivity disorder. J Abnorm Child Psychol, 17(1), 109-125.

Kanay, A. (2006). Dikkat eksikliği hiperaktivite bozukluğu olan 9-13 yaş grubu ilköğretim öğrencilerinin uyumsal davranışları, benlik kavramı ve akademik başarıları arasındaki ilişkiler (Yüksek Lisans Tezi). Dokuz Eylül Üniversitesi Eğitim Bilimleri Enstitüsü Eğitim Bilimleri Anabilim Dalı Rehberlik ve Psikolojik Danışmanlık Programı, İzmir.

Mayberry, W. (1990). Self-esteem in children: Considerations for measurement and intervention. Am J Occup Ther, 44(8), 729-734.

Mazzone, Postorino, Reale ve ark, (2013). Self-esteem evaluation in children and adolescents suffering from ADHD. Clin Pract Epidemiol Ment Health, 9, 96.

Missiuna, C., \& Pollock, N. (2000). Perceived efficacy and goal setting in young children. Can J Occup Ther, 67(3), 101109.

Öner, N. (1996). Piers- Harris Çocuklarda Öz-Kavramı Ölçeği El Kitabı. Türk Psikologlar Derneği, Ankara.

Sarı, M., \& Cenkseven, F. (2008). İlköğretim öğrencilerinde okul yaşam kalitesi ve benlik kavramı. Uluslararası İnsan Bilimleri Dergisi, 5(2), 1-16.

Uluyurt, F. (2012). Bazı değişkenlere göre okul öncesi eğitim kurumlarına devam eden 5-6 yaş grubu çocuklarının akran ilişkileri (Doktora tezi). Selçuk Üniversitesi Sosyal Bilimler Enstitüsü, Konya.

Yavuzer, H. (2000). Eğitim ve gelişim özellikleriyle okul çağı çocuğu. Remzi Kitabevi (5. Basım). İstanbul.

Willoughby, C., King, G., \& Polatajko, H. (1996). A therapist's guide to children's self-esteem. Am J Occup Ther, 50(2), 124-132. 
